\title{
PENGARUH WAKTU AKTIVASI TERHADAP KARAKTERISTIK ADSORBEN DARI KULIT PISANG KEPOK (Musa acuminate L) YANG DIAKTIVASI SECARA FISIKA
}

\section{EFFECT OF ACTIVATION TIME ON CHARACTERISTICS OF BANANA PEELS (MUSA ACUMINATE L) ADSORBENT PREPARED BY PHYSICS ACTIVATION}

\author{
Elvitriana $^{1}$, Vera Viena ${ }^{1}$, Muhammad Nizar ${ }^{1}$, Sari Wardani ${ }^{2}$ \\ ${ }^{1}$ Program Studi Teknik Lingkungan, Fakultas Teknik, Universitas Serambi Mekkah, Banda Aceh - Indonesia \\ ${ }^{2}$ Fakultas Pertanian, Universitas Abulyatama, Aceh Besar - Indonesia \\ Email: elvitriana@serambimekkah.ac.id
}

\begin{abstract}
Abstrak
Penelitian ini bertujuan untuk menganalisis pengaruh waktu aktivasi terhadap karakteristik adsorben dari kulit pisang yang diaktivasi secara fisika. Proses pembuatan adsorben dilakukan melalui 2 tahap yaitu proses karbonasi kulit pisang pada suhu $400{ }^{\circ} \mathrm{C}$ selama 1,5 jam dan proses aktivasi secara fisika yang dilakukan pada suhu $600{ }^{\circ} \mathrm{C}$ selama 15,30 dan 45 menit dengan variasi ukuran 50 dan 100 mesh. Parameter karakteristik adsorben yang diuji adalah kadar air, kadar abu, volatile matter, fixed carbon, daya adsorpsi terhadap iodine, dan penentuan gugus fungsi menggunakan FTIR. Hasil penelitian menunjukkan bahwa karakteristik adsorben dari kulit pisang yang dihasilkan memenuhi SNI No. 06- 3730-1995 dengan nilai kadar air sebesar 2-8 \%, kadar abu 2-9 \%, volatile matter 12-17 $\%$, fixed carbon 73-84 \% dengan daya serap iodine sebesar $952 \mathrm{mg} / \mathrm{g}$. Hasil spektra FT-IR adsorben memiliki spektra pita serapan pada bilangan gelombang $2850-2960 \mathrm{~cm}^{-1}$ muncul vibrasi ulur pada gugus $\mathrm{C}-\mathrm{H}$ dengan intensitas 92,50 dengan waktu aktivasi 45 menit dan ukuran 50 mesh. Berdasarkan hasil uji karakteristik, dapat disimpulkan bahwa adsorben dari kulit pisang memiliki potensi untuk diaplikasikan sebagai salah satu karbon aktif penyerap untuk limbah cair maupun gas.
\end{abstract}

Kata kunci: Karakteristik adsorben, Spektra FTIR, adsorben dari kulit pisang

\begin{abstract}
This study aimed to analyze the effect of activation time on characteristics of banana peels (Musa acuminate $L$ ) adsorbent prepared by physics activation. The adsorbent was prepared through two stages, the carbonation of banana skin conducted at $400{ }^{\circ} \mathrm{C}$ for 1.5 hours and the physics activation process conducted at $600{ }^{\circ} \mathrm{C}$ for 15,30 , and 45 minutes with variations 50 mesh and 100 mesh in size. Adsorbent characteristic parameters analyzed were water content, ash content, volatile matter, fixed carbon, adsorption capacity of iodine, and determination of functional groups using FTIR. Results showed that characteristics of banana peels adsorbent met SNI No. 06-3730-1995 with a water content of $2-8 \%, 2-9 \%$ ash content, $12-17 \%$ volatile matter, fixed carbon $73-84 \%$ with iodine absorption of $952 \mathrm{mg} / \mathrm{g}$. Results of FT-IR spectra, adsorbent has an absorption band spectra at wave number of $2850-2960 \mathrm{~cm}^{-1}$ with stretching vibration appeared on C-H group with intensity 92.50 with activation time of 45 minutes and 50 mesh size. Based on its characteristics analysis, it can be concluded that adsorbent from banana peels has potential to be applied as one of the active carbon absorbent for liquid and gaseous waste.
\end{abstract}

Keywords: Characteristic of Adsorbent, FTIR Spectra, banana peels Adsorbent

\section{Pendahuluan}

Buah Pisang merupakan salah satu penyumbang komoditas buah terbesar bagi Provinsi Aceh yang mencapai 689.892 kuintal [1]. Seiring dengan tingginya produktivitas buah pisang, maka jumlah limbah kulit pisang yang dibuang ke lingkungan meningkat, terutama pada saat musim panen. Hal inilah yang mengakibatkan potensi limbah kulit pisang cukup besar, sehingga diperlukan penanggulangan limbah kulit pisang agar memiliki nilai guna yang lain. Selama ini kulit pisang hanya dimanfaatkan sebagai pupuk atau pakan ternak.

Kulit pisang mengandung senyawa selulosa sebesar $14,4 \%$ yang merupakan polimer sederhana terbentuk dari ikatan kimia yang memiliki permukaan rantai selulosa seragam sehingga dapat membentuk lapisan berpori. Material padatan berpori inilah yang 
menyerap bahan bahan di sekelilingnya, sehingga dapat dimanfaatkan sebagai material penyerap [5]. Adinata [2] telah mengkaji pembuatan karbon aktif menggunakan bahan baku kulit pisang, hasil penelitian menunjukan bahwa kondisi yang terbaik untuk pembuatan karbon aktif dari kulit pisang terjadi pada suhu karbonisasi $400{ }^{\circ} \mathrm{C}$ selama 1,5 jam. Lebih lanjut, penyerapan iodine diperoleh sebesar $45,685 \%$ dengan waktu aktivasi 2,5 jam menggunakan aktivator $\mathrm{H}_{2} \mathrm{SO}_{4}$. Penelitian ini difokuskan untuk mengetahui pengaruh waktu aktivasi terhadap kualitas adsorben dari kulit pisang yang diaktivasi secara fisika

\section{Metodologi Penelitian Bahan dan alat penelitian}

Bahan yang digunakan adalah kulit pisang kepok (Musa acuminate L) diperoleh dari pasar tradisional Kota Banda Aceh, aquades, kertas saring (Whatman) dan bahan kimia berupa larutan iodine, natrium thiosulfate $0,1 \mathrm{~N}$, indikator amilum yang diperoleh secara komersial dari Waco, LTD. Peralatan yang digunakan yaitu: pisau (Stainlees Steel), oven (Memmert), pipet tetes, furnace (Line Thermolyne FB1410M-33 at $1100^{\circ} \mathrm{C}$ ), timbangan (Ahaus), ayakan mesh, masker, gelas ukur, buret, statif, porselin, dan Fourier Transform-Infra Red (FT-IR, Shimadzu IR Prestige 21).

\section{Prosedur Penelitian}

Limbah kulit pisang dibersihkan, dipotong hingga ukuran $\pm 3 \mathrm{~cm}$, dan dikeringkan pada suhu $60^{\circ} \mathrm{C}$ pada oven hingga kering. Proses karbonisasi dilakukan pada suhu $400{ }^{\circ} \mathrm{C}$ selama 1,5 jam. Karbon yang dihasilkan selanjutnya diayak sehingga berukuran 50 dan 100 mesh. Selanjutnya, proses aktivasi dilakukan secara fisika menggunakan furnace pada kondisi suhu $600{ }^{\circ} \mathrm{C}$ selama 15 menit, 30 menit, dan 45 menit. Karbon aktif yang dihasilkan selanjutnya dianalisa untuk mengetahui karakteristik adsorbennya yang meliputi analisa kadar air, kadar abu, daya serap iodium, volatile matter, fixed carbon, dan uji analisa gugus fungsi karbon aktif dengan menggunakan Fourier Transform-Infra Red (FT-IR). Hasil analisa karakteristik dibandingkan dengan Standart Kualitas Karbon Aktif (Standar Nasional Indonesia, SNI No. 06-3730-1995).

\section{Hasil}

\section{Hasil Analisa Uji Kadar Air}

Kadar air sangat berpengaruh terhadap kualitas adsorben, berdasarkan hasil penelitian kadar air pada adsorben dari kulit pisang diperoleh berkisar 2-8 \%. Rendahnya kadar air ini dapat dikarenakan permukaan adsorben lebih sedikit mengandung gugus fungsi yang bersifat polar, sehingga interaksi antara uap air yang bersifat polar juga sedikit [3]. Secara keseluruhan uji kadar air pada adsorben dari kulit pisang telah memenuhi Standar Nasional Indonesia (SNI) No. 06-3730-1995 yaitu sebesar 15\% (maksimum). Hasil analisa uji kadar air adsorben dari kulit pisang disajikan pada Gambar 1.

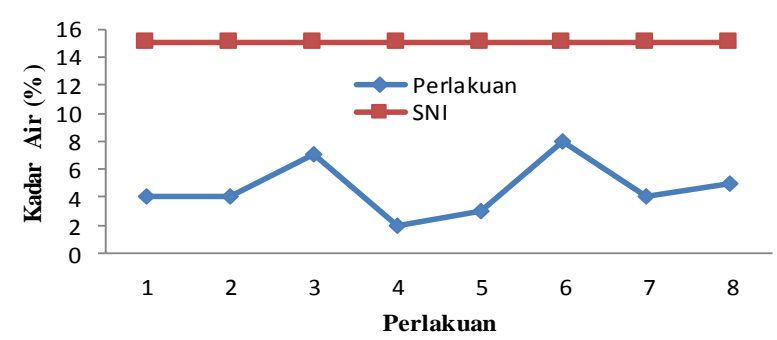

Gambar 1 Hasil analisa uji kadar air adsorben dari kulit pisang (Perlakuan 1: ukuran 50 mesh; Perlakuan 2: ukuran 50 mesh, 15 menit, $600^{\circ} \mathrm{C}$; Perlakuan 3: ukuran 50 mesh, 30 menit, $600^{\circ} \mathrm{C}$; Perlakuan 4: ukuran 50 mesh, 45 menit, $600^{\circ} \mathrm{C}$; Perlakuan 5: 100 mesh, Perlakuan 6: ukuran 100 mesh, 15 menit, $600^{\circ} \mathrm{C}$; Perlakuan 7: ukuran 100 mesh, 30 menit, $600^{\circ} \mathrm{C}$; Perlakuan 8: ukuran 100 mesh, 45 menit, $\left.600^{\circ} \mathrm{C}\right)$

\section{Hasil Analisa Uji Kadar Abu}

Kadar abu merupakan sisa dari pembakaran yang telah tidak memiliki unsur karbon dan nilai kalor lagi. Kadar abu dipengaruhi oleh besarnya kadar silika, semakin besar kadar silika maka kadar abu yang dihasilkan juga semakin besar [3]. Hasil analisa kadar abu adsorben dari kulit pisang disajikan pada Gambar 2.

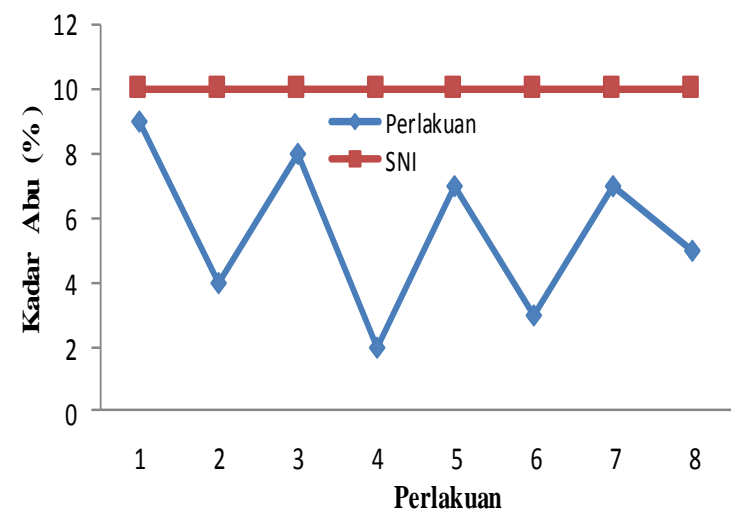

Gambar 2. Hasil analisa kadar abu adsorben dari kulit pisang

(Perlakuan 1: ukuran 50 mesh; Perlakuan 2: ukuran 50 mesh, 15 menit, $600^{\circ} \mathrm{C}$; Perlakuan 3: ukuran 50 mesh, 30 menit, $600^{\circ} \mathrm{C}$; Perlakuan 4 : ukuran 50 mesh, 45 menit, $600^{\circ} \mathrm{C}$; Perlakuan 5: 100 mesh, Perlakuan 6: ukuran 100 mesh, 15 menit, $600^{\circ} \mathrm{C}$; Perlakuan 7: ukuran 100 mesh, 30 menit, $600^{\circ} \mathrm{C}$; Perlakuan 8: ukuran 100 mesh, 45 menit, $600^{\circ} \mathrm{C}$ )

Pengujian kadar abu dilakukan dengan cara pemanasan pada suhu $815^{\circ} \mathrm{C}$ selama 1 jam, kadar abu adsorben dari kulit pisang yang diperoleh berkisar 2$9 \%$. Secara keseluruhan untuk uji kadar abu pada adsorben dari kulit pisang yang diperoleh telah memenuhi SNI No. 06-3730-1995 yaitu sebesar 10\%. 


\section{Hasil Analisa Uji Volatile Matter}

Kadar suatu zat mudah menguap merupakan hasil dekomposisi zat-zat penyusun karbon akibat proses pemanasan selama karbonisasi dan bukan komponen penyusun karbon [3]. Berdasarkan hasil penelitian, nilai volatile matter untuk adsorben dari kulit pisang berkisar antara $12-17 \%$. Rendahnya kadar zat yang menguap dikarenakan oleh menguapnya senyawasenyawa non karbon yang bersifat volatile pada proses karbonisasi.

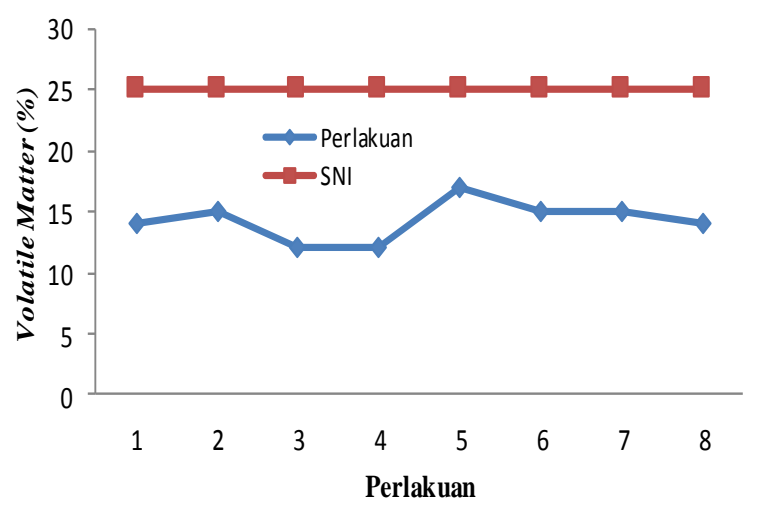

Gambar 3. Hasil analisa uji volatile matter adsorben dari kulit pisang

(Perlakuan 1: ukuran 50 mesh; Perlakuan 2: ukuran 50 mesh, 15 menit, $600^{\circ} \mathrm{C}$; Perlakuan 3: ukuran 50 mesh, 30 menit, $600^{\circ} \mathrm{C}$; Perlakuan 4: ukuran 50 mesh, 45 menit, $600^{\circ} \mathrm{C}$; Perlakuan 5: 100 mesh, Perlakuan 6: ukuran 100 mesh, 15 menit, $600^{\circ} \mathrm{C}$; Perlakuan 7: ukuran 100 mesh, 30 menit, $600^{\circ} \mathrm{C}$; Perlakuan 8: ukuran 100 mesh, 45 menit, $600^{\circ} \mathrm{C}$ )

Secara keseluruhan, untuk hasil uji volatile matter pada adsorben dari kulit pisang yang diperoleh telah memenuhi SNI No. 06-3730-1995 yaitu sebesar $25 \%$. Hasil analisa volatile matter adsorben dari kulit pisang disajikan pada Gambar 3.

\section{Hasil Analisa Uji Fixed Carbon}

Kadar karbon terikat adalah fraksi karbon yang terikat di dalam adsorben selain fraksi air, zat menguap, dan abu. Tinggi rendahnya kadar karbon terikat di dalam adsorben dipengaruhi oleh nilai kadar abu, kadar zat mudah menguap, dan senyawa hidrokarbon yang masih menempel pada permukaan adsorben dan juga dipengaruhi oleh kandungan selulosa dan lignin bahan yang dapat dikonversi menjadi atom karbon [3]. Gambar 4 memperlihatkan nilai kadar karbon terikat pada adsorben dari kulit pisang berkisar antara 73-84\%. Secara keseluruhan, hasil uji fixed carbon pada adsorben dari kulit pisang yang diperoleh telah memenuhi SNI No. 06-37301995 yaitu $65 \%$ (minimum).

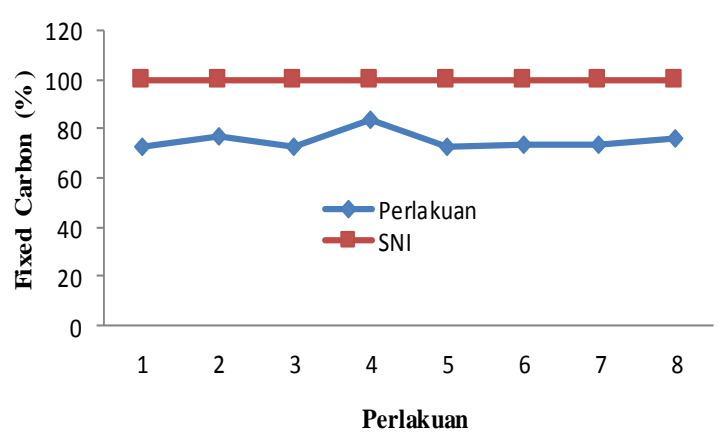

Gambar 4. Hasil analisa uji fixed carbon pada adsorben dari kulit pisang

(Perlakuan 1: ukuran 50 mesh; Perlakuan 2: ukuran 50 mesh, 15 menit, $600^{\circ} \mathrm{C}$; Perlakuan 3: ukuran 50 mesh, 30 menit, $600^{\circ} \mathrm{C}$; Perlakuan 4 : ukuran 50 mesh, 45 menit, $600^{\circ} \mathrm{C}$; Perlakuan 5: 100 mesh, Perlakuan 6: ukuran 100 mesh, 15 menit, $600^{\circ} \mathrm{C}$; Perlakuan 7: ukuran 100 mesh, 30 menit, $600^{\circ} \mathrm{C}$; Perlakuan 8: ukuran 100 mesh, 45 menit, $600^{\circ} \mathrm{C}$ )

\section{Hasil Analisa Uji Kemampuan Daya Serap Terhadap Iodin}

Parameter yang dapat menunjukkan kualitas adsorben adalah daya adsorpsi terhadap larutan Iodium. Semakin besar bilangan iodiumnya, maka semakin besar kemampuan penyerapannya. Gambar 5 memperlihatkan Hasil uji daya serap iodine pada adsorben dari kulit pisang. Hasil analisa uji kemampuan daya serap iodium pada penelitian ini diperoleh berkisar antara 761-952 mg/g. Secara keseluruhan untuk uji daya serap iodine pada adsorben dari kulit pisang yang diperoleh telah memenuhi SNI No. 06-3730-1995 yaitu 750 mg/g (minimum).

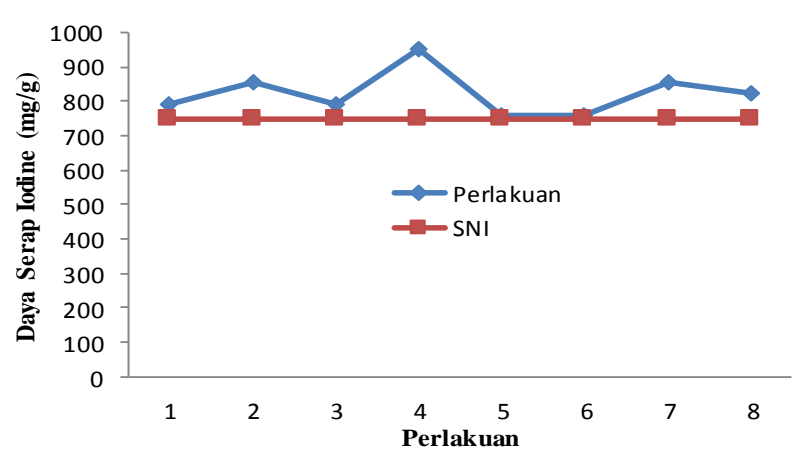

Gambar 5. Hasil uji daya serap iodine pada adsorben dari kulit pisang

(Perlakuan 1: ukuran 50 mesh; Perlakuan 2: ukuran 50 mesh, 15 menit, $600^{\circ} \mathrm{C}$; Perlakuan 3: ukuran 50 mesh, 30 menit, $600^{\circ} \mathrm{C}$; Perlakuan 4: ukuran 50 mesh, 45 menit, $600^{\circ} \mathrm{C}$; Perlakuan 5: 100 mesh, Perlakuan 6: ukuran 100 mesh, 15 menit, $600^{\circ} \mathrm{C}$; Perlakuan 7: ukuran 100 mesh, 30 menit, $600^{\circ} \mathrm{C}$; Perlakuan 8: ukuran 100 mesh, 45 menit, $600^{\circ} \mathrm{C}$ ) 


\section{Hasil Analisa Gugus Fungsi Arang Aktif (FTIR)}
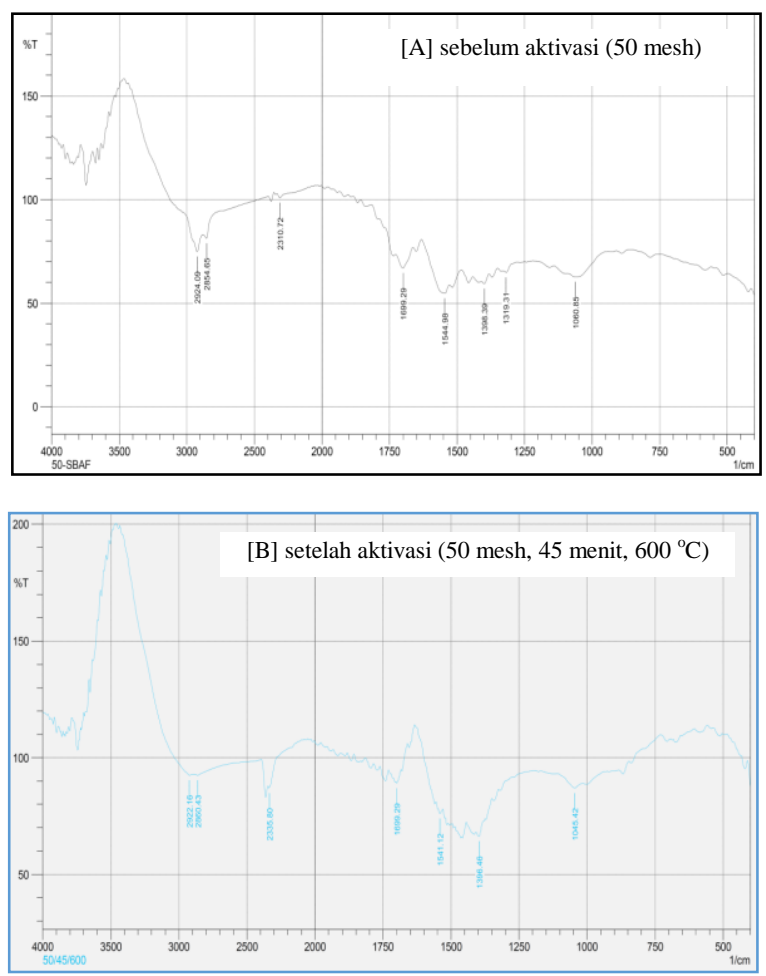

Gambar 6. Hasil Analisa FTIR adsorben dari kulit pisang $[\mathrm{A}]$ sebelum aktivasi (50 mesh) dan [B] setelah aktivasi (50 mesh, 45 menit, $600{ }^{\circ} \mathrm{C}$ )

Gambar 6A dan 6B menunjukkan perbandingan bilangan gelombang pita serapan karbon dari kulit pisang sebelum dan setelah aktivasi pada ukuran 50 mesh. Pita serapan karbon dari kulit pisang sebelum dan setelah teraktivasi mengalami perubahan, hal ini dikarenakan activating agent yang dapat menyebabkan terjadinya pergeseran berdasarkan lingkungan kimianya. Pada Gambar 6B terlihat daerah serapan berada pada posisi $2850-2960 \mathrm{~cm}^{-1}$ yaitu mengandung gugus fungsi C-H. Sebelum aktivasi frekuensi gugus $\mathrm{C}-\mathrm{H}$ berada pada intensitas 81,23 , sedangkan setelah aktivasi terjadi peningkatan intensitas gugus $\mathrm{C}-\mathrm{H}$ yaitu sebesar 92,50. Tinggi rendahnya intensitas pada nilai gugus fungsi $\mathrm{C}-\mathrm{H}$ dipengaruhi oleh kandungan $\mathrm{H}_{2} \mathrm{O}$. Semakin tinggi kandungan $\mathrm{H}_{2} \mathrm{O}$ maka intensitas gugus $\mathrm{C}-\mathrm{H}$ semakin rendah

\section{Kesimpulan}

Hasil uji karakteristik adsorben dari kulit pisang yang diaktivasi secara fisika pada suhu $600{ }^{\circ} \mathrm{C}$ dengan perlakuan berbagai waktu aktivasi menunjukkan bahwa kadar air, kadar abu, volatile matter, fixed carbon dan serapan terhadap Iodine masih berada di bawah standar SNI 06-3730-95. Berdasarkan hasil uji tersebut, maka dapat disimpulkan bahwa adsorben dari kulit pisang ini memiliki potensi untuk diaplikasikan sebagai salah satu karbon aktif penyerap untuk limbah cair maupun gas.

\section{Ucapan Terima Kasih}

Terima kasih yang sebesarnya diucapkan kepada Kemenristek Dikti yang telah membiayai seluruh penelitian ini melalui dana DIPA Kopertis Wilayah 13 Tahun 2016, Nomor : 763/K13.2.2/UM/2016.

\section{Daftar Pustaka}

[1] BPS, Produksi Komoditas Buah-Buahan Aceh, Badan Pusat Statistik Provinsi Aceh. 2001.

[2] M. R. Adinata, Pemanfaatan Limbah Kulit Pisang sebagai Karbon Aktif, Thesis, Jurusan Teknik Kimia, Fakultas Teknologi Industri, Universitas Pembangunan Nasional, Jawa Timur, 2013.

[3] N. Fauziah, Pembuatan Arang Aktif Secara Langsung Dari Kulit Acacia Mangium Wild dengan Aktivasi Fisika dan Aplikasinya Sebagai Adsorben, Departemen Hasil Hutan, Fakultas Kehutanan, Institut Pertanian Bogor, 2009.

[4] SNI (1995), Arang Aktif Teknis, Standar Nasional Indonesia, SNI No. 06-3730-1995, Departemen Perindustrian RI: 1999 , p. $29-57.3$

[5] W.N.S, Nasir, Nurhaeni, dan Musafira, Pemanfaatan arang aktif kulit pisang kepok (Musa normalis) sebagai adsorben untuk menurunkan angka peroksida dan asam lemak bebas minyak goreng bekas, Online Journal of Natural Science, 3 (1), 2014, p. 18 - 30. 